\title{
Organizational Learning and Job Complexity as Predictors of Commitment among Employees at Nestle Ghana Limited
}

\author{
Prince Addai $^{{ }^{*}}$, Isaac Nti Ofori ${ }^{2}$, John Avor $^{3}$, Daniel Ntiamoah Tweneboah ${ }^{4}$ \\ ${ }^{1}$ Department of Industrial Psychology, University of Fort Hare, P/B X1314, Alice, Republic of South Africa, 5700 \\ ${ }^{2,4}$ Department of Human Resource Management, Zenith University College, Box TF 511, Trade Fair, Accra \\ ${ }^{3}$ Teaching Staff, Vine Christian School, Box KD 714, Kanda, Accra
}

\begin{abstract}
The study examined organizational learning and perceived job complexity as predictors of commitment among employees at Nestle Ghana Limited. One hundred and twenty (120) employees were selected using the convenience sampling to complete the Dimensions of Learning Organization Questionnaire, Job Diagnostic Survey and Organizational Commitment Questionnaire. The findings were determined with the independent $t$ test, the Pearson $r$ and regression analyses. Findings indicated that employees who perceived high job insecurity were less committed than those who perceived low job complexity. A significant positive relationship was found between organizational learning and employee commitment. Individual learning accounted for more variance in organizational commitment compared to group and organizational components of learning organization. These stand to reason that to improve employees' commitment, management needs to dedicate a lot of efforts in creating a conducive environment that encourages learning and also redesign complex jobs that meet the knowledge, skills and abilities of employees.
\end{abstract}

Keywords - employee commitment, job complexity, organizational learning, individual learning, group learning.

\section{INTRODUCTION}

Indeed the commitment of employees has been a subject of concern to many employers as well as customers. The antecedent factors contributing to organizational commitment should therefore not be undermined. Research on factors influencing organizational commitment over the years suggests that many talented and highly skilled professional workers leave their organizations not on the basis of meager salaries or poor security benefits but because employees are not empowered to act proficiently. Organizational learning and designing less complex jobs are some of the ways of empowering employees which most organizations have neglected (Weber \& Antal, 2003). To ensure maximum commitment of employees through empowerment, there is the need to assess how these factors influence organizational commitment in order to make it part of the culture of the organization.

Organizational Commitment is the degree to which an employee is willing to maintain membership to an organization due to the interest and association with the organization's goals and values (Miller, 2003). Committed employees believe in and accept the organization goals, exert considerable effort on behalf of the organization, and also maintain organizational membership (Miller, 2003). Employees commit to the organization for various reasons. As indicated by Meyer and Allen (1991), some people commit themselves to their jobs because of the love they have for what they do or because of what they will lose when they leave the organization. Others also commit themselves to the organization because they feel dutybound to the organization (Bodla \& Danish, 2009).

There are three components of organizational commitment: affective, continuance and normative commitment. Affective commitment refers to the "employee's emotional attachment to, identification with, and involvement in, the organization" (Meyer, Stanley, Herscovitch \& Topolnytsky, 2002, p.21). An employee who is affectively committed strongly identifies with the organization's goals and values and desires to remain part of the organization (Meyer \& Allen, 1991). Continuance commitment on the other hand is the willingness of an employee to remain in the organization because of the perceived cost associated with the investment made towards nontransferable investments such as the employee's relationships with others within the organization (Martin, 2011). Normative commitment is based on an employee's feeling of obligation to their workplace. Weiner (2002) discussed normative 
commitment as being a generalized value of loyalty and duty.

As explained by DeCotis and Summers (2007), a significant number of factors predict organizational commitment but emphasis should be geared towards the factors that ensure employee empowerment. In a study by Joo and Lim (2009), it was revealed that organizational learning and job complexity are relevant factors that empower employees to commit themselves to organizational goals and values. This makes the characteristics of the job and organizational learning important predictors of employees' commitment (Atak, 2011).

Organizational learning refers to "an organization skilled at creating, acquiring, and transferring knowledge, and at modifying its behaviour to reflect new knowledge and insights" (Garvin, 1993, p. 80). In a learning organization, employees continuously expand their capacity and develop new ways of thinking which help to create the results they truly desire because relevant, practical information are constantly provided by the organization to its employees (Owoyemi, Oyelere \& Elegbede, 2011). Learning organizations provide continuous opportunities for employees to acquire knowledge that link individual performance with organizational performance (Joo \& Lim, 2009). The basic rationale for such organizations is that in situations of rapid change, only those that are flexible, adaptive and productive will excel and be able to adapt to the competitive market (Baek-Kyoo \& Shim, 2010).

Organization learning can take place on three levels which include individual, group and organizational levels (Senge, 1994). Individual level is the change of skills, insights, knowledge, attitudes and values acquired by a person through self-study, technology-based instruction, and observation (Marquardt, 2002). Continuous learning at the individual level is regularly changing behaviour based on deepening and broadening of one's skills, knowledge and world view. Group learning is a process in which a team takes action, reflects upon feedback and makes changes to adapt (Pawlowsky, 2000). Team learning bridges the transfer of individual learning to organizational knowledge that can then be shared by all (Pawlowsky, 2000). Learning at the organizational level takes place through the medium of individuals and their interactions (Probst \& Buchel, 1997). A learning organization actively engages in creativity, capturing and mobilization of knowledge to enable it adapt to a changing environment (Probst \& Buchel, 1997).

For employees to commit themselves to the core values of the organization, organizations need to build their core competencies and to develop their knowledge, skills and abilities that make them withstand the competitive market (Sung, 2009). In order to improve an employee's commitment, organizations must ensure that organizational members continuously extend their learning activities since the acquisition of knowledge, skills and abilities through continuous learning create a fit between the individual and the organization (Baek-Kyoo \& Shim, 2010). Effective organizational learning does not only equip job incumbents, but also those yet to be employed (Garvin, 1993). This is because the experiences, beliefs, and norms that are accumulated through effective organizational learning shape the ideas of future employees and the direction of the organization (Paul \&Anatharaman, 2004).

Organizational commitment is also influenced by the complexity of the job (Joo \& Lim, 2009). When employees are not succeeding on a job, it affects the individual commitment level. The problem of not succeeding on a job can be related to how complex the job descriptions are (Dornstein \& Matalon, 1998). Employees' level of commitment is also affected when they are not challenged enough to work above their capacity (Gomez-Mejia, Balkin \& Cardy, 2007). Thus, for a job to improve employees' commitment, it must neither be too complex nor too easy (Gomez-Mejia, Balkin \& Cardy, 2007). Performing a task which is too complex can lead to frustration and psychological distress and eventually decrease employee commitment because of the inability of the employee to perform the task demands (Joo \& Lim, 2009). Too easy tasks also decrease commitment because of its inability to challenge the employees. As indicated by Hackman and Oldham (2000), job descriptions that are within the capacity of the employee challenge the employee to work diligently with minimal external control and elicit higher level of commitment among employees. This means that the level of the complexity will determine how committed employees will be.

In line with above discussions, the study was carried out to investigate the relationship between organizational learning and organizational commitment and also find out which of the components of organizational learning account for higher variance in organizational commitment. The study also assessed the influence of job complexity on organizational commitment.

\section{LITERATURE REVIEW}

The compatibility between employees and the organization is a necessary condition which determines certain decisive employee behaviours such as commitment. According to the Person-Organizational (P-O) framework, to empower employees to elicit favourable behaviours, there is the need 
to create congruence between the individual values and the attributes of the job. Continuous learning is one way of empowering employees (Noe, Hollenbeck, Gerhart, \& Wright, 2005). When employees engage in continuous learning, they acquire skills and abilities that make them able to fit into the attribute of the job. Moreover, when employees believe they can perform their task responsibilities though demanding, it serves as a form of empowerment since it creates $\mathrm{P}-\mathrm{O}$ fit and influence employees to act proactively to achieve their goal.

Several studies have documented the impact of organizational learning on employee's commitment. These studies have indicated a positive relationship between organizational learning and employee commitment (Atak, 2011, Baek-Kyoo \& Shim, 2010; Ng, Butts, Vandenberg, DeJoy \& Wilson, 2006; Sung, 2009). A study was conducted by Kalyar, Rafi and Ahmad (2012) to assess the relationship between organizational learning and organizational commitment among employees in Pakistan. The findings revealed that organizational commitment is positively predicted by organizational learning. The researchers indicated that to keep pace with the changing environment, organizations need to remain flexible and improve their employees' commitment through organizational learning. Similarly, Gua-Pak, Kasim, and Uli (2008) indicated a significantly positive relationship between organizational learning and organizational commitment.

Wang (2005) conducted a study on the relationship between the components of organizational learning and organizational commitment in the University of Minnesota. The findings indicated that all the components of organizational learning had a significant relationship with the dimensions of organizational commitment. Individual level was however found to predict higher variance in commitment than the team and learning at the organizational level.

Extant studies on the relationship between job complexity and organizational commitment have revealed contradictory findings. Some studies (Hrebiniak \& Alutto, 1992; Khatibi, Asadi \& Hamidi, 2009) have indicated a negative relationship between job complexity and organizational commitment. A study was conducted by Vijaya and Hemamalini (2012) with the purpose of examining how organizational commitment is influenced by role ambiguity, role conflict and faculty work role balance in engineering colleges. The study indicated that role ambiguity and role conflict negatively predict organizational commitment. Parasuraman and Alutoo's (1992) study also showed that organizational commitment was negatively predicted by job complexity.

Though, the studies above give evidence of a negative relationship between job complexity and organizational commitment, some studies have also discovered no significant relationship between them. For example, a study by Katerberg, Hom and Hulin (2004) revealed that complexity of the job was not significantly related to organizational commitment. Randall (2006) also found no significant relationship between job complexity and organizational commitment. On the contrary, Joo and Lim (2009) found a significant positive relationship between job complexity and organizational commitment.

Despite the massive advances in understanding the determinants of organizational commitment, a number of relevant issues are yet to be fully resolved (Atak, 2011; Sung, 2009). For example studies have not exclusively assessed which dimension of organizational learning predicts significant variance in organizational commitment to help in training decisions. So far, there has been no empirical study that links organizational learning and perception of job complexity with employees' commitments in the Ghanaian context. This study therefore attempts to bridge this gap and further deepen understanding in this area of research.

What is more, the researchers predict that there will be a significant positive relationship between organizational learning and employee commitment. Also, individual learning is predicted to account for higher variance in organizational commitment compared to group and organizational learning. Finally, the researchers predict that employees who perceive higher level of job complexity will be less committed compared to employees who perceive lower level of job complexity.

\section{METHOD}

\subsection{Design}

A cross-sectional survey design was employed in this study. The study measured phenomena that were not directly observable, for which the cross-sectional survey was considered to be an appropriate way to capture the findings from a large population at one time (Gall, Gall \& Borg, 2007). This design was also deemed appropriate because it expedites asking a large number of employees their opinions in a relatively short time and cost effective fashion (Addai, Ofori, Bioh \& Avor, 2017).

\subsection{Population}

Employees at Nestle Ghana Limited served as the population. Nestle Ghana Limited manufactures and markets locally well-known Nestle brands. The business 
activity of Nestle Ghana Ltd has a direct contribution to the economy of Ghanaian. Nestle Ghana Limited was selected because it is one of the world's leading manufacturing companies that produce nutritious food and is conscious of the importance of informing the consumer about the link between nutrition and health. Also, the population was convenient and readily available to the researchers. Three regional offices (Tema, Accra and Koforidua regional offices) formed the research settings. The three regional offices were selected to obtain relatively large number of participants for the study.

\subsection{Participants}

The convenience sampling technique was used to select one hundred and twenty (120) respondents for the study. The convenience sampling technique was used because it was very easy to carry out with few rules governing how the sample was collected. Only respondents who were willing to participate in the study were selected regardless of their age, sex, religion and educational level. The 120 respondents consisted of sixty-eight (68) males and fiftytwo (52) females between the ages of 19 and 49 years, with a mean age of 32.15. The mean years of working experience of the respondents was 6.72 years with educational level ranging from basic school to master's degree (See Table 1 for description of the demographic characteristics)?

Table.1: Demographic characteristics of the Respondents

\begin{tabular}{llll}
\hline $\begin{array}{l}\text { Demographic } \\
\text { Variables }\end{array}$ & $\begin{array}{l}\text { Male } \\
(n=68)\end{array}$ & $\begin{array}{l}\text { Female } \\
(n=52)\end{array}$ & $\begin{array}{l}\text { Total } \\
(n=120)\end{array}$ \\
\hline Years of Work Experience & $\begin{array}{l}\text { Mean }(S D) \\
7.02(4.37)\end{array}$ & $\begin{array}{l}\text { Mean }(S D) \\
6.42(3.74)\end{array}$ & $\begin{array}{l}\text { Mean }(S D) \\
\text { Educational Level }\end{array}$ \\
$\begin{array}{l}\text { Basic } \\
\text { HND }\end{array}$ & 5 & 8 & \\
First Degree & 26 & 17 & 13 \\
Masters & 32 & 25 & 43 \\
Age of Employees & 5 & 2 & 57 \\
Below 20 years & & & 7 \\
20-30 years & 6 & 10 & \\
31-40 years & 24 & 16 & 16 \\
Above 40 years & 28 & 8 & 40 \\
\hline
\end{tabular}

\subsection{Measures}

A four-section questionnaire was used. The first section of the questionnaire consisted of 4 items assessing the demographic characteristics of respondents such as gender of the employee, years of working experience, educational level and age. The second, third and fourth sections of the questionnaire measured organizational learning, job complexity and organizational commitment respectively.

Organizational learning was measured using the Dimensions of the Learning Organization Questionnaire (DLOQ) developed by Watkins and Marsick (1997). The DLOQ consisted of 42 items capturing three dimensions of organizational learning: individual level, group or team level and organizational level. The DLOQ has a Cronbach alpha of .87 (Garvin, 1993). Response to the DLOQ is on a five-point scale ranging from Strongly Agree (4) to Strongly Disagree (0). Scores for the DLOQ ranged from 0 to 168 . Score of each dimension of DLOQ ranged from $0-$ 56. A higher score reflected higher organizational learning.
A sample of the items on the DLOQ is "My organization enables people to get needed information at anytime quickly and easily".

Perceived job complexity was also measured with the Job Diagnostic Survey (JDS; Hackman \& Oldham, 1980) which assessed the challenges and complexity of employee jobs. The scale consists of 23 items measuring five job characteristics which include autonomy, feedback, still variety, task identity and task significance. The Cronbach alpha of the JDS is .79 (Oldham \& Cummings, 1996). The JDS was scored based on the response participants provided by selecting an option from a five-point Likert scale ranging from Strongly Disagree (4) to Strongly Agree (0). The maximum possible score awarded was 92 and the minimum possible score was 0 . A total score of $0-45$ on the JDS indicated low level of job complexity whereas a total score of $46-92$ indicated a high level of job complexity. An example of an item is "I have almost complete 
responsibility for deciding how and when the work is to be done".

Organizational commitment was measured with the Organizational Commitment Questionnaire (OCQ) by Allen and Meyer (1990). The OCQ contains twenty four (24) items measuring three components of organizational commitment including affective, continuance and normative commitments. The Cronbach alpha coefficient for the scale is .87 (Allen \& Meyer, 1990). The scale is scored based on responses from the five-point Likert scale ranging from Strongly Agree (4) to Strongly Disagree (0). The maximum possible score awarded was 96 and the minimum possible score was 0. An typical item from the OCQ is "I really feel as if this organisation's problems are my own".

\subsection{Procedure for Data Collection}

Introductory letters were sent to the three regional offices of the Nestle Ghana Limited in Tema, Accra and Koforidua. This served as means of obtaining permission to undertake the research in the selected regional offices of the Nestle Ghana Limited. When permission was obtained from the regional offices of the organization, willing respondents were selected from the regional offices and given the selfadministered questionnaires in an envelope to complete. The administering of the questionnaires lasted for three weeks.

\section{DATA ANALYSIS}

Descriptive and inferential statistics were used for the analysis. The inferential statistics (Pearson $r$, independent ttest and Regression Analysis) were used in analyzing the three hypotheses stated. The Pearson $r$ was used to analyze the relationship between organizational level and employee commitment predicted in hypothesis 1 . This is because the relationship between two variables was sought. The amount of variance accounted for by the three components of organizational learning on employee commitment was compared using the regression analysis. This is because the focus was to compare the amount of variance that accounted for employee commitment using the three components of organizational learning. The differences in employee commitment between respondents who perceived higher level of job complexity and those who perceived lower job complexity was analyzed using the independent ttest. This is because the mean scores of two different groups were compared.

\section{RESULTS}

The analysis of data was done with the aid of the version 20 of the Statistical Package for Social Science. The 95\% confidence level was used.

\subsection{Hypotheses Testing}

The first hypothesis $\left(\mathrm{H}_{1}\right)$ predicted that there will be a significant positive relationship between organizational learning and employee commitment. The Pearson $\mathrm{r}$ results are presented in Table 2.

The second hypothesis $\left(\mathrm{H}_{2}\right)$ predicted thatindividual learning will account for higher variance in commitment compared to group and organizational learning. The regression analysis results are presented in Table 3.

Hypothesis 3: Employees who perceive lower level of job complexity will be more committed compared to employees who perceive higher level of job complexity. The independent t-test results are presented in Table 4.

Table.2: Pearson Product-Moment Correlation between Organizational Learning and Employee Commitment

\begin{tabular}{lcccc}
\hline Variable & Mean & Std Deviation & $\boldsymbol{r}$ & $\boldsymbol{P}$ \\
\hline Organizational Learning & 85.43 & 13.55 & $.436^{* *}$ & .000 \\
Employee Commitment & 59.08 & 12.32 & & \\
\hline
\end{tabular}

Table.3: Regression Analysis Result of the Levels of Organizational Learning as Predictors and Organizational Commitment as the Criterion Variable

\begin{tabular}{llccccc}
\hline Model & & $\mathrm{B}$ & Std. Error & $\beta$ & $\mathrm{t}$ & $\mathrm{P}$ \\
\hline Step 1 & (Constant) & 39.055 & 4.550 & & 8.58 & .000 \\
& Individual & .653 & .145 & .384 & 4.52 & .000 \\
Step 2 & (Constant) & 25.204 & 6.620 & & 3.80 & .000 \\
& Individual & .572 & .145 & .337 & 3.96 & .000 \\
& Group/Team & .274 & .184 & .139 & 1.49 & .139 \\
& Org Learning & .321 & .199 & .148 & 1.61 & .110 \\
\hline
\end{tabular}

$\mathrm{R}^{2}=.148$ for step $1, \mathrm{R}^{2}=.204$ for step $2, \Delta \mathrm{R}^{2}=.148$ for step $1, \Delta \mathrm{R}^{2}=.056$ for step $2, * * * p<.001$ 
Table.4: Summary of Independent t test results of the Influence of Job Complexity on Employee Commitment

\begin{tabular}{lcccccc}
\hline Job Complexity & N & Mean & SD & Df & $\boldsymbol{t}$ & $\boldsymbol{P}$ \\
\hline Low Complexity & 56 & 67.78 & 7.87 & 118 & 9.64 & .000 \\
High Complexity & 64 & 51.45 & 10.30 & & & \\
\hline
\end{tabular}

From Table 2, it is evidnced that a significant positive relationship exist between organizational learning and employee commitment $(r=.436, p<.05)$. This supports the first hypothesis, meaning, a significant positive relationship exists between organizational learning and employee commitment.

Table 3 depicts that individual learning, group learning and organizational learning accounted for $34 \%(\beta=.337, p<$ $.001), 14 \%(\beta=.139, p=.139)$ and $15 \%(\beta=.148, p=.110)$ of variances respectively in predicting organizational commitment. Assessing their respective t-values, individual learning $(\mathrm{t}=3.96)$ accounted for higher prediction in organizational commitment followed by organizational learning $(\mathrm{t}=1.61)$ and team learning $(\mathrm{t}=1.49)$. This supports the second hypothesis which indicates that individual learning predicts more level of employee commitment compared to organizational and team learning.

As shown in Table 4, job complexity had a significant impact on employee commitment $\left(t_{(118)}=9.64, p<.05\right)$. This stands to mean that the mean score of commitment among employees who perceived low job complexity ( $M=67.78$, $\mathrm{SD}=7.87$ ) was significantly higher than those who perceived high job complexity $(\mathrm{M}=51.45, \mathrm{SD}=10.30)$. This also supports the third hypothesis. This means that employees who perceive lower level of job complexity are more committed than those who perceive higher level of job complexity.

\section{DISCUSSION}

The results of the study supported the first hypothesis by revealing a significant positive relationship between organizational learning and employee commitment. This stands to reason the more employees engage in continuous learning, the higher they become committed to the organization. This finding is consistent with results from a study conducted by Atak (2011) which indicated that organizational learning is positively related to employees' commitment. This study's finding also corroborates the findings of Gua-Pak et al. (2008) which established that learning organization increases organizational commitment. As explained by Kalyar, Rafi and Ahmad (2012), to keep pace with the changing environment, organizations need to remain flexible and improve their employees' commitment via organizational learning. The reason for the result can be explained with the social empowerment theory (Kanter,
1993). As implied by the social empowerment theory, engaging in organizational learning empowers employees to have autonomy in performing their duties effectively and take responsibility of the organization. When employees also perceive that they will be held responsible for the outcome of the organization, they commit themselves to ensure that the goals of the organization are achieved.

The result of the study again revealed that individual learning accounts for more variance in organizational commitment compared to group and organizational learning. This means that learning at the individual learning leads to higher level of employee commitment compared to learning at the group and also learning at the organizational levels. This finding supports that of Chan (2002) which indicated that learning at the individual level predicts higher variance in organizational commitment compared to learning at both the group and organizational levels. The higher amount of commitment predicted by individual level of learning compared to group and organizational levels of learning can be explained based on the fact that organizational commitment is an individual-based construct and that is affected by individual factors than team and organizational factors. As iterated by Wang (2005), individual learning unlike the other levels of organizational learning aims at developing the competencies of the employees. The development of the competencies of employees empowers them and increases their level of commitment knowing that the organization has their wellbeing at heart. Moreover, Nonaka (1991) indicated that new knowledge for all the three levels of organizational level always begins with the individual. Therefore, if organizational level predicts organizational commitment, then individual level which is the basis for all levels of learning will contribute significantly higher to commitment among the employees.

Finally, employees who perceived lower level of job complexity were more committed compared to employees who perceive higher level of job complexity. This finding means that complex jobs hinder employee commitment. This finding is equally consistent with some researches (eg. Khatibi, et al., 2009; Vijaya \& Hemamalini, 2012), which suggested that the higher the complexity of job responsibilities, the lower the level of employee commitment. One possible explanation to be made for the above finding was proffered by Parasuraman and Alutoo 
(1992); they claimed that complexity of jobs increases the level of stress among employees which make them uncomfortable to stay in the organization and subsequently decreases their level of commitment. Moreover, complex jobs do not create congruence between the individual values and the attribute of the job leading to lower level of commitment.

There are some precincts that limit the interpretation of the results. First, the study relied only on self-report measures which are subject to social desirability effects. The perceptual nature might affect the true reflection of the actual behaviour of the respondents. In addition, the use of convenience sampling makes it difficult to generalize the findings to the larger population. Lastly, aspects of this study were correlational in nature and thus cause-effect relationship cannot be inferred.

Aside the weaknesses, the study had some implications worthy of mentioning. The findings of the study imply that organizational learning elicits commitment among employees. Organizations must therefore engage in continuous learning. The findings also imply that management must target the development of individual knowledge, skills and abilities since individual learning predicted higher commitment compared to group and organizational learning. The findings also provided additional evidence that complex jobs decrease employees' commitment. Therefore, there is the need to redesign jobs to make them less complex.

Based on the significant influence of organizational learning and job complexity on employee commitment, the researchers recommend to human resource managers the need to help increase the commitment levels of employees by establishing continuous organizational learning, and redesigning jobs to make them less complex. Again, employers are entreated to consider the development of employee job specifications since it predicts more commitment than group and organizational specifications. Finally, future research should continue to examine other personal and contextual factors of the work environment that influence organizational commitment.

The following recommendations may also be offered for further studies: Firstly, there is the need for future researchers to deeply assess the components of a complex job that influence organizational commitment. This can better be done using mixed method approach. Moreover, there is also the need to engage in more integrative approach, in which multiple personal characteristics such as gender, tenure of work, age, educational level and rank of work can be assessed simultaneously. In this regard, more research on the moderating and mediating effects of demographic characteristics on the relationships between the predictors and the outcome variable can be assessed.

\section{CONCLUSION}

The findings of this study have established that organizational learning significantly explained variance in organizational commitment. Individual learning accounted for more variance in organizational commitment compared to all the other components (group and organizational) of organizational learning. Employees who perceived lower level of job complexity were also more committed than those with higher level of job complexity. The findings imply that to increase employees' commitment, organizations must engage in continuous learning. The higher amount of variance accounted by individual learning also implies that leaning in organizations must target development of individual competencies. Again, there is the need to redesign jobs to make it less complex for employees to be able to perform efficiently.

\section{REFERENCES}

[1] Addai, P., Ofori, N. I., Bioh, R. \& Avor, J. (2017). Attitude towards Women in Managerial Positions: A study among Undergraduate Students of the University of Ghana. International Journal of English Literature and Social Sciences, 2(5), 1 - 8

[2] Allen, N. J., \& Meyer, J. P. (1990).The measurement and antecedents of affective, continuance, and normative commitment to the organization.Journal of Occupational Psychology, 63, 1-18.

[3] Baek-Kyoo, J. \& Shim, J. (2010). Psychological empowerment and organizational commitment: the moderating effect of organizational learning culture. Industrial Review, 425-441

[4] Bodla, M. A. \& Danish, R. Q. (2009).Politics and workplace: an empirical examination of the relationship between perceived organizational politics and work performance. South Asian Journal of Management, 16(1), 44-62.

[5] Chan, C. C. A. (2002). Individual, team and organizational learning: underpinnings of competitive advantage. $\mathrm{PhD}$ thesis, Murdoch University.

[6] DeCotis, T. \& Summers, T. (2007)."A path analysis of a model of the antecedents and consequences of organizational commitment".Human Relations Journal, 40, 445-470.

[7] Dornstein, M., \& Matalon, Y. (1998).A comparative analysis of predictors of organizational commitment.A study of voluntary army personnel in Isreal.Journal of Vocational Behaviour, 34(2),192-203. 
[8] Gall, M. D., Gall, J. P., \& Brog, W. R. (2007).Education Research: An Introduction (8th ed.). Boston: Allyn and Bacon.

[9] Garvin, D. A. (1993). Building learning organizations. Harvard Business Review, 71(4), 78-91.

[10] Gomez-Mejia, L. R., Balkin, D. B., \& Cardy, R. L. (2007). Managing Human Resources ( $5^{\text {th }}$ ed.). Upper Saddle River, NJ: Pearson.

[11] Gua-Pak, O., Kasim, R. S. R. \& Uli, J. (2008). The effect of organizational learning on job commitment, job satisfaction and work performance in Malaysia: a mediation analysis. Management-Journal, 39(5): 761895.

[12]Hackman, J. R. \& Oldham, G. R. (1980).Work redesign. Reading, MA: Addison-Wesley.

[13]Hrebiniak, L. G., \& Alutto, J. A. (1992). Personal and role related factors in the development of organizational commitment. Administrative Science Quarterly, 17, 555-572.

[14] Joo, B. \& Lim, T. (2009). The effects of organizational learning culture, perceived job complexity, and proactive personality on organizational commitment and intrinsic motivation. Journal of Leadership and Organizational Studies, 16(1), 48-60.

[15] Kalyar, M., N., Rafi, N., \& Ahmad, B. (2012). Organizational learning and organizational commitment: A correlational study in manufacturing context. African Journal of Business Management, 6(9), $3349-3355$.

[16] Kanter, R.M. (1993). The change masters. New York: Simon \& Schuster.

[17] Katerberg, R. J., Hom, P. W., \& Hulin, C. L. (2004). Effects of job complexity on the reactions of part-time employees, Baltic Journal of Management, 1(5), 196 212

[18] Khatibi, A., Asadi, H. \& Hamidi, M. (2009). The Relationship between Job Stress and Organizational Commitment in National Olympic and Paralympic Academy. World Journal of Sport Sciences, 2(4), 272278

[19] Marquardt, M. J. (2002). Building the LO: Mastering the 5 elements for corporate learning. Davies-Black Publishing, Palo Alto, California.

[20]Martin, M. J. (2011). Influence of Human Resource Practices on Employee Intention to Quit.Journal of Economic Psychology, 32, 312-623.

[21] Meyer, J. P. \& Allen, N. J. (1991). A Tree-component Conceptualization of Organizational Commitment. Human Resource Management Review, 1, 61-89.
[22]Meyer, J., P. Stanley, D. J., Herscovitch, L. \& Topolnytsky L. (2002). Affective, Continuance, and Normative Commitment to the Organization: A Metaanalysis of Antecedents, Correlates, and Consequences. Journal of Vocational Behaviour, 61, $20-52$

[23] Miller, D. B. (2003).Managing Professionals in Research Development.San Francisco, CA: JosseyBass.

[24] Ng, T. W. H., Butts, M. M., Vandenberg, R.J., DeJoy, D.M. \& Wilson, M. G. (2006). Effects of management communication, opportunity for learning, and work schedule flexibility on organizational commitment. Journal of Vocational Behaviour, 68, 474-489.

[25] Noe, R. A., Hollenbeck, J., Gerhart, B., \& Wright, P. (2005).Human resource management: Gaining a competitive advantage (6th ed.). New York: McGrawHill.

[26] Nonaka, I. (1991). The dynamic theory of organizational knowledge creation. Organizational Science Review, 5(1), 14-37.

[27] Oldham, G.R. \& Cummings, A. (1996). Employee creativity: personal and contextual factors at work. Academy of Management Journal, 39 (3), 607-634.

[28] Owoyemi, O. A., Oyelere, M. \& Elegbede, T. (2011).Enhancing Employees' Commitment to Organization through Training.International Journal of Business and Management, 6(7), 280 - 286

[29] Parasuraman, S. \& Alutoo, J. A. (1992). Sources and outcomes of stress in Organizational settings: Towards the development of a structural model. J of Org Psyc, $3(6), 118-126$

[30] Paul, A. K., \& Anantharaman, R. N. (2004).Influence of HRM practices on organizational commitment: A study among software professionals in India', Human Resource Development Quarterly, 15(1), 77-88.

[31]Pawlowski, B. (2000). The biological meaning of preferences on the human mate market.Przeglad Antropologiczny Anthropological Review, 63, 66-72.

[32]Probst, G. J. B. \& Buchel, B. S. T. (1997).Organizational learning: the competitive advantage of the future. New York: Prentice Hall.

[33]Randall, D. M. (2006).Multiple roles and organizational commitment.Journal of Organizational Behaviour,9 (4), 309-317

[34] Senge, P. (1990). The Fifth Discipline. The art and practice of the learning organization, London: Random House.

[35] Sung, J. (2009).The Influences of Learning Organization Culture, Organizational Commitment, 
and Organizational Citizenship Behaviours.Harvard

Business Review, 95-104.

[36] Vijaya T. G. \& Hemamalini, R. (2012). Role Ambiguity, Role Conflict and Work Role Balance: Influence on Organizational Commitment and Turnover Intension of Faculty. European Journal of Social Sciences, 30 (4), 574-585

[37]Wang, X. (2005).Relationship among organizational learning culture, job satisfaction, and organizational commitment in Chinese state-owned and privatelyowned enterprises.Unpublished doctoral dissertation, University of Minnesota.

[38] Weber, C., \& Antal, B. A. (2003).The role of time in organizational learning.In Dierkes, M., Antal, B. A., Child, J. \& Nonaka, I. (Eds.), Handbook of organizational learning and knowledge (pp. 351-368). New York: Oxford University Press, Inc.

[39] Weiner, Y. (2002). Commitment in Organization: A Normative View. Academy of Management Review,7, 418-428. 